\title{
Fatores que dificultam a perda de peso em mulheres obesas de graus I e II
}

\author{
Factors that difficult the loss of weight in obese women of degrees I and II \\ Factores que impiden la pérdida de peso en mujeres obesas de grados I y II \\ Ana Paula da Silva Vasques Oliveira ${ }^{1}$ \\ Marilia Marques da Silva \\ Universidade Católica de Brasília
}

\begin{abstract}
Resumo
O estudo tem o objetivo de investigar fatores que dificultam a perda de peso em cinco mulheres obesas de graus I e II. Os dados foram coletados e analisados a partir de entrevistas e a aplicação da escala de figuras de Stunkard e o questionário dos três fatores alimentares. Foi verificado que as participantes querem emagrecer para ter uma maior proximidade com suas identidades. Apresentam uma expectativa de que o emagrecimento melhore outras áreas da vida, como o relacionamento com as pessoas. Acreditam que as mulheres sofrem mais em relação ao peso do que os homens em nossa sociedade, pois são mais influenciadas a ter um corpo magro. A obesidade causa sofrimento para as entrevistadas, ao mesmo tempo em que o ato de comer é tido como um tranquilizador, uma forma de diminuir a ansiedade e a angústia.

Palavras-chave: Obesidade feminina; Família; Fatores emocionais; Aspectos psicossociais.
\end{abstract}

\begin{abstract}
The study aims to investigate factors that hinder weight loss in five obese, grades I and II, women. Data were collected and analyzed from interviews and the application of the scale of Stunkard figures and the three dietary factors questionnaire. It was found that the interviewees want to lose weight to have a closer relationship with their identities. There is an expectation that weight loss will improve other areas of life, such as personal relationships. They believe that women suffer more in relation to weight than men in our society because they are more influenced to have a lean body. We conclude that obesity causes suffering to the interviewees, while the act of eating is regarded as calming, a way to reduce anxiety and anguish.

Key-words: Obesity female; Family; Emotional factors; Psychosocial aspects.

\section{Resumen}

El estudio tiene como objetivo analizar los factores que dificultan la pérdida de peso en cinco mujeres obesas en grados I y II. Se realizó una entrevista semi-estructurada y aplicada a escala figuras de Stunkard y el cuestionario de tres factores dietéticos. Se encontró que las entrevistadas quieren perder peso para tener una relación más próxima con sus identidades. Existe la expectativa de que la pérdida de peso mejora otras áreas de la vida, tales como las relaciones con la gente. Ellas creen que las mujeres sufren más en relación con el peso que los hombres en nuestra sociedad, ya que son más influenciados a tener un cuerpo delgado. Llegamos a la conclusión de que la obesidad causa sufrimiento a las entrevistadas, mientras que el acto de comer produce calma, una forma de reducir la ansiedad y la angustia.

Palabras- clave: Obesidad femenina; Familia; Factores emocionales; Aspectos psicosociales.
\end{abstract}

\section{Considerações Iniciais}

A obesidade é um problema de saúde pública, uma doença crônica que deve ser tratada por longos períodos e acompanhada por uma equipe de profissionais da área de saúde (Nunes et al. in Freitas, 2006). Existe atualmente um marcante aumento na prevalência da obesidade em quase todos os países latinos-americanos (Kac \& Meléndez, 2003). No Brasil, dados recentes da Vigilância de Fatores de Risco e Proteção para Doenças Crônicas por Inquérito Telefônico (VIGITEL, 2010) comprovam que cerca de $48,1 \%$ da população está com excesso de peso

Endereço 1: Quadra 21 Casa 91 Setor Leste Gama. CEP: 72460210, Brasília, DF, Brasil. e $15 \%$ com diagnóstico de obesidade, sendo que o percentual da obesidade em mulheres aumentou em $4,1 \%$ de 2006 para 2010.

Cohen e Cunha (2004) apontam que boa parcela dos obesos não come mais que a maioria das pessoas, mas ingere mais calorias, principalmente na forma de gordura e praticam menos atividades físicas. Hoje é reconhecido que a obesidade tem várias causas, para que ela se desenvolva, vários fatores agem em conjunto. Sendo assim, não se pode culpar a falta de "força de vontade" para emagrecer como o fator principal da obesidade.

Este estudo tem o objetivo de identificar os fatores sociais, familiares, biológicos e emocionais que podem dificultar a perda de peso em mulheres obesas de graus I e II que querem emagrecer. Verificase também sobre a interferência destes fatores na 
adesão ao tratamento e sobre a ocorrência de ganhos que contribuem para que mulheres em sofrimento em relação ao próprio corpo permaneçam obesas.

A obesidade é um fato complexo, que envolve diversos fatores sociais, familiares, biológicos e emocionais que interagem entre si. A má alimentação, o consumo de dietas inadequadas, os estilos de vida sedentários, a tendência natural para o excesso de peso, a facilidade com que se encontram alimentos calóricos, os hábitos familiares, a correria do dia a dia e o aumento do tamanho das porções dos alimentos facilitam a ocorrência da obesidade. Sendo uma questão multifatorial necessita de uma abordagem interdisciplinar para sua compreensão, diagnóstico e tratamento, pois mais do que pela herança genética, a obesidade está diretamente relacionada a fatores ambientais, sociais e comportamentais (Donato et al., 2007).

Fatores sociais: Para Meier e Ferreira (2004, p. 9) "o nosso peso não é apenas uma carga que temos que carregar, é uma consequência do nosso estilo de vida, do que somos, de como pensamos e agimos". Assim áreas da vida das pessoas podem ser afetadas pela obesidade.

Mudar um estilo de vida, bem como um hábito alimentar pode levar ao isolamento social em função dos indivíduos deixarem de sair com os amigos ou com a família para evitar ingerir alimentos muitas vezes, inadequados. Para Ribeiro (2008) o indivíduo que se encontra acima do peso ideal pode ter dificuldade de se relacionar sexualmente com outra pessoa, pois é natural que o obeso se sinta sexualmente indesejável e quando a autoestima está baixa normalmente evita-se contato com outras pessoas.

Em relação ao ambiente de trabalho, Zanella (2006) afirma que mulheres desempregadas são mais propensas à obesidade se comparadas às mulheres com empregos fixo, já entre os homens ocorre o inverso. Quanto à escolaridade, a pesquisa da Vigitel (2010) mostra que quanto maior o nível de escolaridade das mulheres menor a presença da obesidade, já entre os homens quanto maior o nível de escolaridade maior a presença da obesidade.

Referente à adolescência Rabello e Passos (2010) ao estudar Erikson e a teoria psicossocial do desenvolvimento, apontam que a preocupação com a opinião alheia faz com que o adolescente modifique suas atitudes constantemente, remodelando várias vezes a sua personalidade. Nesta confusão de identidade é comum que ele sinta-se vazio, isolado e ansioso. Por não sentir-se suficientemente seguro o indivíduo prefere isolar-se, numa atitude de se "preservar". Neste sentido, pode-se pensar que o fato de o sujeito obeso resistir ao emagrecimento seja uma forma de afirmar sua identidade, mesmo que seja excluído pela sociedade, como uma maneira de se resguardar. Sendo a identidade construída e mantida pela sociedade, o indivíduo obeso que provavelmente sofreu algum tipo de preconceito pela sua condição física, pode vir a agir defensivamente, querendo preservar sua forma física como um modo de se reafirmar. O sentimento de identidade é experimentado como uma sensação de bem estar, o sentimento de "estar em casa" em nosso próprio corpo, de "saber para onde se vai" e uma certeza íntima de ser reconhecido pelos outros (Erikson, 1987). No entanto, Collins e Sprinthall (2003) afirmam que é comum para os jovens terem sentimentos negativos acerca do seu corpo, das suas relações com a família, com os colegas e sobre as perspectivas para o futuro.

Para Erikson (1998) a sociedade pode sentir-se rejeitada pelo indivíduo que parece não se importar com ser aceitável, sendo assim, condena aqueles que ela não pode compreender ou absorver. Para a comunidade a mudança desejável é percebida como uma simples questão de força de vontade, já a resistência a uma mudança é percebida como uma questão de má vontade ou de inferioridade. Percebese que a obesidade sendo uma problemática social e apesar de ser bastante conhecida cientificamente é incompreendida pela sociedade, o que pode trazer um sofrimento para as pessoas obesas.

Novaes (2005) aponta que ao vermos uma pessoa bonita parecemos desculpar todo e qualquer tipo de "defeito de caráter" que esta pessoa possa ter, aos belos, tudo é desculpado e permitido. Já em relação às pessoas gordas surgem comentários depreciativos. De dever social a beleza tornou-se um dever moral. O fracasso do emagrecimento passa a ser visto como uma incapacidade individual e não uma impossibilidade mais ampla. Este estigma social de acordo com Almeida (2013) pode levar as mulheres obesas a uma exclusão social.

Fatores familiares: Collins e Sprinthall (2003) citam que a família tem uma função importante em ajudar a criança a estabelecer uma continuidade entre as aprendizagens da infância e as exigências da adolescência e da vida adulta. Os papeis e comportamentos aprendidos devem ser transformados em comportamentos e papeis a desempenhar no futuro. Neste sentido, a família ajuda o sujeito, que dela depende, a adquirir autonomia e prepara os adolescentes para assumir os papeis da vida adulta. Entre os padrões repassados pelas famílias, estão os relacionados à alimentação. Dados de pesquisas como a de Venturini (2000) revelam que negar alimento significa negar afeto ou cuidados básicos. "Uma proporção significativa de adolescentes com excesso de peso mantém a corpulência na vida adulta e os hábitos alimentares estabelecidos na infância e adolescência" (Vargas et al., 2011), torna-se importante a prevenção do ganho de peso nas idades mais jovens, sendo os pais determinantes na aquisição de hábitos saudáveis nos primeiros anos de vida e também na manutenção de novos hábitos.

No entanto, muitas vezes, a família, assim como 
os grupos sociais e a sociedade como um todo, não são favoráveis e nem receptivos às mudanças que o indivíduo opta fazer para alcançar o emagrecimento (Meier \& Ferreira, 2004). Tal fato pode vir a prejudicar o indivíduo no sentido de desmotivá-lo a realizar um tratamento adequado.

Fatores biológicos: Cohen e Cunha (2004) alegam que a probabilidade dos filhos serem obesos será de $7 \%$ se os pais forem magros, $40 \%$ se um dos genitores for obeso e $80 \%$ a $85 \%$ se ambos os genitores forem obesos. Porém, apenas a hereditariedade não determina se uma pessoa será obesa, pois a obesidade é produto da vulnerabilidade genética, de fatores ambientais ou comportamentos mal adaptativos. Quando os pais estão com sobrepeso ou são obesos a tendência é que os filhos também o sejam. Porém, muitos outros fatores contribuem para o desenvolvimento da obesidade, como predisposição genética, estilo de vida, fatores socioculturais e étnicos, além de maus hábitos alimentares e a falta de exercício físico.

Uma pesquisa realizada no Laboratório de Sinalização Celular da Faculdade de Ciências Médicas da Unicamp mostrou que algumas áreas do cérebro de pessoas obesas revelam padrões distintos de funcionamento quando comparadas às de pessoas magras. Para Velloso (2011), é possível que em pessoas obesas, algum erro no processamento de informações que chegam ao sistema nervoso central possa ocorrer.

A obesidade também pode estar ligada a alterações endócrinas, como o mau funcionamento das glândulas da tireóide, hipófise e supra-renais. Porém, de acordo com Zanella (2006) o hipotireoidismo raramente é a causa da obesidade, sendo muito difícil as doenças endócrinas desencadearem o aumento de peso. A autora aponta que os ovários policísticos podem contribuir para a obesidade, onde quanto maior o peso do paciente, mais grave se torna a doença e vice-versa.

Fatores emocionais: A obesidade pode levar à morte do corpo físico devido a diversas doenças que podem vir a causar, porém, uma grande quantidade de peso pode "matar" subjetivamente o indivíduo também. Mata sua vontade de sair, de se relacionar com outras pessoas, de fazer sexo, dançar, de viver, enfim.

Meier e Ferreira (2004) afirmam que a obesidade pode causar várias feridas emocionais. Existe não apenas um ideal de corpo, mas um ideal de vida no qual só se pode ser feliz sendo magro. O indivíduo, ao enxergar a obesidade como fonte de todos os problemas de sua vida, não precisa se preocupar com dificuldades emocionais e sim em controlar o peso. Porém conhecer os aspectos emocionais associados à obesidade é importante para que compreenda que a obesidade pode trazer inúmeros desconfortos, além de angustias e sentimentos de inferioridade, mas também prazer.
Muitas vezes "comemos os nossos sentimentos em vez de senti-los" e comemos quando não sentimos fome fisiológica, mas vontade de nos alimentar (Meier \& Ferreira, 2004, p.15). Existem pessoas que ao invés de sentirem fome física, sentem fome psicológica, e assim não precisam estar com fome para alimentarse, preenchem o "vazio" que sentem com a comida, o que é ineficaz, pois esse vazio é impossível de ser preenchido com a comida. “... em uma visão psicossomática, a doença é um desequilíbrio interno provocado por um desequilíbrio vivencial, uma maneira que o psiquismo encontra para adaptar-se a uma realidade adversa", (Meier \& Ferreira, 2004, p. 11).

O descontrole alimentar pode revelar excesso de controle pela pessoa em outras áreas da vida, excessiva rigidez com ela mesma e com os outros, alto grau de perfeccionismo e dificuldade em adiar a satisfação do prazer. Dessa forma, a rigidez leva ao descontrole alimentar, funcionando como uma "válvula de escape", uma forma de compensação, o que favorece sentimentos de impotência e fracasso. Meier e Ferreira (2004, p. 27) apontam ainda que "o comer" pode alimentar emoções profundas, assim é necessário administrarmos nossas emoções que levam ao descontrole alimentar para mantermos a qualidade da nossa saúde, pois a emoção pode ter o poder de aniquilar a razão.

\section{Metodologia}

Pelos objetivos e forma de abordagem deste estudo optou-se pela pesquisa qualitativa. $\mathrm{Na}$ pesquisa qualitativa cabe ao pesquisador decifrar o significado da ação humana, e não apenas descrever comportamentos, sendo fundamental que se considere todos os fenômenos como igualmente importantes (SILVA et al, 2006). Uma das finalidades que a pesquisa pode ter é de ajudar o participante a obter a autodeterminação (GUNTHER, 2006).

Utilizou-se para a coleta dos dados uma entrevista semi-estruturada, a escala de figuras de Stunkard e o questionário dos três fatores alimentares (Nunes et al. in Freitas, 2006). Para a análise dos dados foi utilizada a análise de conteúdo. Na análise qualitativa selecionam-se as categorias sem tratar exaustivamente todo o conteúdo (BARDIN, 2009).

A pesquisa foi aprovada pelo comitê de ética da Universidade Católica de Brasília - CEP/UCB 055/2010.

Participantes: Cinco mulheres (nomes fictícios) pertencentes à mesma classe socioeconômica (média), com idades entre 21 e 33 anos de idade, residentes em Brasília. A escolha de apenas mulheres como participantes deste estudo se deu pelo fato de a obesidade ser um problema que preocupa mais as mulheres do que os homens, como pode ser observado na cultura brasileira. Almeida (2013) afirma que do 
ponto de vista cultural sexista cresce o preconceito e a discriminação em relação às mulheres obesas, pois seus corpos não fazem parte do padrão que a sociedade valoriza.

Três participantes apresentaram na ocasião das entrevistas obesidade de grau I e duas participantes com grau II. Todas com tentativas e fracassos de emagrecer e/ou manter a perda de peso, e que nunca realizaram cirurgia estética. Foi considerado o Índice de Massa Corpórea (IMC) para definir o grau de obesidade das participantes. O IMC encontrado nas entrevistadas variou entre 30,10 a 39,30.

Alessandra é casada há um ano, dona de casa, tem 21 anos de idade, sem filhos e nível médio completo. Atualmente apresenta um IMC de 30,10 tem obesidade de grau I. De acordo com Kakeshita e Almeida (2006), o IMC normal está entre 18,50 e $24,90 \mathrm{~kg} / \mathrm{m}$, para alcançar esse resultado é necessário que Alessandra perca 15 quilos.

Larissa tem 33 anos de idade, é casada há 12 anos, dona de casa, mãe de quatro filhos e possui nível médio completo de escolaridade. O IMC atual de Larissa é 34,00, o que correspondente à obesidade de grau I. Para que Larissa alcance o seu peso ideal seria necessário perder 23 quilos.

Marina tem 24 anos de idade, é solteira, não tem filhos e está cursando o nível superior. Seu IMC de 35,1 , quadro de obesidade de grau II. Seu peso para ter um IMC adequado, seria de no máximo 65 quilos, para isso precisaria perder 27 quilos.

Priscila tem 29 anos de idade, é casada há sete anos, tem uma filha, trabalha como professora de uma escola particular e possui nível superior completo. Seu IMC é de 31,60, está com obesidade de grau I. Para alcançar o peso ideal deve pesar no máximo 59 quilos, ou seja, teria que emagrecer 17 quilos.

Samanta é solteira, estagiária e não tem filhos, tem 24 anos de idade e nível superior incompleto. Seu IMC é de 39,30, que está incluso na obesidade de grau II. O peso ideal para Samanta é 62 quilos. Para isso, teria que perder 36 quilos.

Coleta de dados. Os dados foram coletados por meio de uma entrevista semi-estruturada, pela aplicação da escala de figuras de Stunkard e do questionário dos três fatores alimentares (Nunes et al. in Freitas, 2006). O contato inicial com as participantes foi realizado por meio telefônico, os dados foram coletados nas residências das participantes, onde o foi explicado mais detalhadamente sobre o que consistia a pesquisa. O Termo de Consentimento Livre e Esclarecido (TCLE) foi apresentado. As participantes concordaram com os termos do TCLE e assinaram o documento.

No início do processo de coleta de dados, a pesquisadora pesou e mediu as participantes para verificar o IMC de cada uma. Após a concordância e a assinatura do TCLE, ocorreu a entrevista, seguida pela aplicação da escala e do questionário. Foi realizado apenas um encontro com cada uma das participantes, que durou em média uma hora e vinte minutos.

\section{Instrumento}

Foram aplicados três instrumentos para a coleta de dados: entrevista semiestruturada; escala de figuras de Stunkard e Questionário dos três fatores alimentares (Nunes et al. in Freitas, 2006). .

A entrevista abordou questões relativas aos sentimentos atuais e passados em relação ao próprio corpo e sobre as tentativas de se perder peso. Buscaramse também os conhecimentos que as participantes têm sobre a obesidade; sua rotina e a rotina de sua família em relação à alimentação; questões sobre os relacionamentos sociais e às expectativas referentes ao emagrecimento. As entrevistas foram gravadas e transcritas literalmente.

A escala de figuras de Stunkard (Nunes et al. in Freitas, 2006), possibilita avaliar o grau de insatisfação corporal e a superestimativa do tamanho corporal. Nesta escala são apresentados nove desenhos femininos em traje de banho (maiô), onde cada figura é mais volumosa que a anterior, sendo a mais magra a primeira e a mais corpulenta a nona. Para a avaliação da insatisfação corporal o entrevistado deve escolher o desenho que mais se aproxima do seu corpo atual e o que mais se aproxima do seu corpo ideal (aquele que gostaria de ter). A diferença entre a figura atual e a ideal serve como medida da insatisfação corporal, onde quanto maior a discrepância, maior a insatisfação. Toma-se como parâmetro o desenho 3 e 6, que correspondem respectivamente aos IMC $20 \mathrm{~km} / \mathrm{m}^{2}$ e $30 \mathrm{~km} / \mathrm{m}^{2}$. A versão em português desse instrumento mostrou-se válida como uma medida de imagem corporal (Nunes et al. in Freitas, 2006).

O questionário dos três fatores alimentares (Nunes et al. in Freitas, 2006) é constituído por 51 questões sobre o comportamento alimentar, sendo dividido em três subcategorias: restrição cognitiva (21 itens), desinibição (16 itens) e fome percebida (14 itens). Estudos com pessoas obesas indicam que um alto escore na escala de restrição e baixo escore na escala de desinibição estão associados com o sucesso na perda e manutenção do peso.

\section{Resultados e Discussão}

\section{Entrevistas}

Os dados das entrevistas foram analisados pelo Método de Análise de conteúdo de Bardin (2009). Pela regra da homogeneidade da análise de conteúdo, as entrevistas devem referir-se ao mesmo tema, terem sido obtidas por intermédio de técnicas idênticas e serem realizadas por indivíduos semelhantes. Essa regra pode ser utilizada quando se deseja comparar entre si os resultados individuais.

Neste estudo, as respostas de cada entrevista foram 
agrupadas em categorias que abrangiam os objetivos da pesquisa. Posteriormente foi efetuada a análise de seu conteúdo. O eixo temático Porque perder peso é tão difícil? foi dividido em quatro categorias: Questões sócio econômicas que interferem no meu peso; A família ajuda ou atrapalha?; Meu organismo e meu peso; e Aspectos emocionais e meu peso.

Porque perder peso é tão difícil?

Questões sócio econômicas que interferem no meu peso: Pelo relato das participantes, foi visto que diversos fatores sociais são considerados como prejudiciais para que ocorresse o emagrecimento. A falta de dinheiro e de tempo para adquirir e preparar alimentos mais saudáveis levava ao consumo de alimentos de fácil preparo e altamente calóricos. A falta de tempo também foi relacionada à forma em que a alimentação ocorria: pular refeições, fazer poucas refeições durante o dia e comer em horários inadequados. Segundo Scagliusi e Palacow (2006), o aumento na frequência de ingestão alimentar pode ajudar no controle do peso corporal, por controlar a sensação de fome e promover uma diminuição da quantidade dos alimentos nas refeições subseqüentes. Portanto, um padrão alimentar onde há o consumo de refeições menores mais vezes ao dia, o que não é o caso das participantes, ajudaria na perda de peso.

Oliveira (2013) em um estudo realizado em 2011 verificou que, a obesidade teve um custo de $\mathrm{R} \$ 487,98$ milhões para o Sistema Único de Saúde do Brasil. Tais custos relacionados com doenças e agravos poderiam ter sido evitados se a obesidade tivesse sido prevenida. Porém, de acordo com a autora, existem outros custos relacionados à obesidade. Pessoas obesas são menos contratadas, demoram a ser promovidas e tem qualidade de vida reduzida. Além disso, podem ter depressão, ansiedade, baixa autoestima e sofrer discriminação.

Alessandra, Marina e Larissa alegam restringir-se de algumas atividades sociais para evitar exposições. Para Ribeiro (2008) o indivíduo que não está bem com o seu corpo não tem vontade de fazer planos, sair, visitar amigos e fazer sexo. Zottis e Labronici (2003) constataram em sua pesquisa que a negação do corpo, o isolamento e a baixa autoestima são comportamentos frequentes observados em pessoas obesas. Tais sentimentos podem gerar a autodecepção e a autoinsatisfação.

A família ajuda ou atrapalha?: O fato de ter alimentos que não são saudáveis em casa foi citado pelas participantes como prejudicial ao emagrecimento. Na hora da escolha de um alimento, afirmaram escolher geralmente o alimento mais fácil de ser consumido, que é muitas vezes o mais calórico, como comidas prontas congeladas e biscoito recheado.

Stein e Ramos (2000) afirmam que a família é responsável pela formação do comportamento alimentar do indivíduo, tendo os pais o papel de primeiros educadores nutricionais. As estratégias que os pais utilizam para a criança alimentar-se pode apresentar estímulos adequados ou inadequados na aquisição das preferências alimentares e no autocontrole da ingesta alimentar durante toda a vida do sujeito. Foi constatado na pesquisa realizada pelos autores que a preocupação dos pais centra-se na quantidade da alimentação, e não em desenvolver hábitos e atitudes direcionados a padrões de alimentação mais adequados. Além disso, a família também exerce uma importante influência na adesão ao tratamento de obesidade. É freqüente que alguns membros da família não concordem em mudar os hábitos alimentares da casa. Quando isso ocorre, a pessoa que está fazendo dieta passa a ter uma alimentação diferenciada da dos demais membros da casa, pelo fato destes não acompanhá-la, o que dificulta à adesão a dieta.

A dificuldade de colaboração na dieta pelas famílias de Samanta, Priscila e Alessandra, contribuía para que as participantes não se sentissem apoiadas. Para Venturini (2000) seria ideal que as famílias tivessem consciência dos benefícios que o controle alimentar pode trazer, seja nos âmbitos físico, social ou emocional e se percebessem como parte integrante no processo alimentar, chegando a mudar os hábitos alimentares de toda a família.

Meu organismo e meu peso: Relatos referentes aos fatores biológicos foram apresentados pelas participantes somente quando se falou sobre facilidade para ganhar peso, ansiedade e gravidez. Cohen e Cunha e (2004) avaliando históricos médicos de alguns pacientes obesos verificaram em quais momentos na vida estas pessoas começaram a ganhar peso. Nota-se que geralmente o ganho de peso ocorre quando há mudanças na rotina das pessoas como mudança de emprego, casamento, divórcio, nascimento de filhos, menopausa, após ter parado de fumar ou de praticar atividade física. Fett et al. (2010) afirmam que durante a gravidez muitas mulheres passam a ter um estilo de vida sedentário, o que colabora para a instalação da obesidade.

Aspectos emocionais e meu peso: Todas as participantes relataram que muitas vezes não conseguiam se controlar, ou seja, comer pouco ou se privar de determinados alimentos e acabavam burlando a dieta ao comer massas e doces. Este descontrole aumentava a dificuldade para manter o peso quando se perdia alguns quilos. Assim, comer muito, comer só o que gosta e comer massas e frituras era muito mais freqüente do que seria necessário para a manutenção e/ou a perda de peso.

Cohen e Cunha (2004) afirmam que a perda de peso e a manutenção do mesmo dependem muito da forte motivação pessoal. Porém, após algum tempo, é natural que a disciplina diminua, pois é difícil manterse fiel a uma dieta com restrições e exclusão de alguns alimentos. Fatores econômicos, emocionais e sociais, 
como a ocorrência de festas e comemorações, podem levar as escapadas, que com o tempo se tornam cada vez mais usuais e podem levar até mesmo ao abandono da dieta.

Sentimentos como saudade da família que mora longe, ficar nervosa, inquieta, triste e irritada foram citados como elementos que colaboram para que as participantes se sintam mais ansiosas e busquem o alimento, provavelmente como uma forma de fugir destes sentimentos. Priscila, Marina e Alessandra afirmam comer quando estão ansiosas, buscando assim, atenuar a ansiedade.

Estas mesmas participantes afirmam que para as mulheres é mais difícil estar acima do peso se comparadas aos homens. Para Pinheiro e Maciel (2007), existem valores sociais associados à magreza que a tornariam almejada pelas mulheres. Atualmente tem-se a impressão da existência de um corpo padrão que seria o melhor para todas as mulheres: o corpo magro. Este corpo é frequentemente exposto positivamente na Mídia, o corpo esbelto procurado pelas mulheres nos dias de hoje exprime as exigências desse novo tipo de mulher. Almeida (2013) cita que a mídia insiste ser o padrão de magreza desejado e alcançável a todas as mulheres. Para Junior (2007) a frase "As muito feias que me perdoem, mas beleza é fundamental" de Vinicius de Morais traduz a ideia de que a beleza está profundamente associada à mulher e ao papel que ela desempenha na sociedade em que está inserida. É uma concepção de que a beleza é uma obrigação feminina.

Gonçalves (2004) afirma que a gordura corporal pesa mais para as mulheres em vários aspectos, pois elas são mais influenciadas pela sociedade a terem um corpo magro. Além disso, como geralmente é a mulher quem se ocupa das tarefas domésticas e cuidam dos filhos precisam ser ágeis e ter uma boa capacidade de se locomover, sendo que a obesidade dificulta o desempenho dessas tarefas e traz tristeza às mulheres obesas. A autora alega que a obesidade, por ser uma construção social pode ser sentida como mais prejudicial para um gênero do que para outro.

\section{Escala de figuras de Stunkard}

De acordo com os resultados obtidos na escala de figuras de Stunkard, sobre a percepção corporal observou-se que Larissa, Priscila e Marina fazem uma boa leitura da imagem corporal, sendo esta compatível com o cálculo do IMC. Alessandra superestima o tamanho corporal e Samanta minimiza o tamanho do seu corpo, ou seja, ambas possuem uma distorção da imagem corporal. Observa-se que Larissa e Priscila possuem pouca insatisfação corporal, Samanta possui uma insatisfação corporal média e Alessandra e Marina apresentam uma grande insatisfação corporal.

Observa-se que de acordo com os resultados da escala, quatro participantes marcaram que gostariam de estar com o IMC ideal (entre 18,50 e 24,90).
Apenas Larissa marcou que gostaria de ter um peso (este seria o seu peso ideal), que pelos critérios de IMC seriam de sobrepeso.

\section{Questionário dos Três Fatores Alimentares}

O Questionário dos Três Fatores Alimentares permite avaliar se o indivíduo tem facilidade para obter sucesso ou não na perda e manutenção do peso (Nunes et al. in Freitas, 2006). Um alto escore na escala de restrição e baixo escore nas escalas de desinibição e fome percebida sugerem que o indivíduo apresenta maior facilidade na perda e manutenção do peso, já um baixo escore na escala de restrição e alto escore nas escalas de desinibição e fome percebida indicam que o indivíduo apresenta uma maior dificuldade na perda de peso e na manutenção dessa perda.

Os dados obtidos no questionário indicam que para Larissa, Priscila, Marina e Alessandra há um baixo escore na escala de restrição e alto escore na escala de desinibição e fome percebida, o que sugere que estas participantes têm dificuldade na perda e manutenção do peso. Apenas em Samanta verificouse um alto escore na escala de restrição e baixo escore nas escalas de desinibição e fome, o que sugere um maior sucesso na perda e manutenção do peso. Porém, Samanta está inserida em um contexto familiar que não propicia o emagrecimento, pelo fato de todos os seus membros serem obesos. A obesidade faz parte desta família e neste contexto todos os membros afetam e são afetados por ela. Para Pratta e Santos (2007) a família ainda hoje exerce um importante papel no desenvolvimento de seus membros, pois a criança se desenvolve no contexto familiar e nele permanece por um longo período de tempo.

Conclui-se que Larissa e Priscila (obesidade grau I) apresentam uma dificuldade na perda de peso e manutenção dessa perda, possuem uma boa percepção corporal e tendem a estarem menos insatisfeitas com seu corpo. Na entrevista elas afirmam não gostarem do seu corpo e não conseguirem ser firmes ao realizar uma dieta, ou seja, não terem disciplina. Cohen e Cunha (2004) afirmam que a falta de "força de vontade" para emagrecer não é a única responsável para que se tenha um insucesso na perda de peso, pois vários fatores agem em conjunto.

Marina que tem obesidade grau II, também possui uma boa percepção do tamanho de seu corpo, mas uma grande insatisfação, ou seja, ela consegue identificar o tamanho de seu corpo sem que haja alguma distorção, porém não está satisfeita com ele. Em sua entrevista relata sentir-se feia, desinteressante e ter raiva de si mesma por ter deixado as coisas chegarem ao ponto que chegou. De acordo com o Questionário dos Três Fatores Alimentares ela possui dificuldade na perda e manutenção do peso. Dados da entrevista revelam que ela sente vontade de comer doce o tempo todo, além de comer só o que gosta e comer rápido de mais, o que interfere em suas tentativas de perder peso. Para 
Nakamura (2007) existe um padrão de beleza corporal socialmente desejado que quando não obtido gera frustrações e insatisfação, já que a percepção do corpo e da beleza está relacionada à cultura e à sociedade.

Alessandra (grau I) superestima o tamanho corporal e apresenta uma grande insatisfação indicando uma distorção de imagem e uma baixa autoestima. $\mathrm{Na}$ entrevista afirma se sentir mal quando a roupa não serve e se preocupa com o que os outros vão pensar ou falar a respeito do seu corpo. O Questionário dos Três Fatores Alimentares revela que Alessandra possui uma dificuldade na perda e manutenção do peso e na entrevista ela afirma que não gosta de praticar atividades físicas e fazer redução alimentar, além de sempre estar exposta a alimentos, o que dificulta suas tentativas de obter o emagrecimento. Para Gorayeb e Luiz (2002), realizar atividades físicas regularmente e fazer uma reeducação alimentar aumenta a possibilidade de o indivíduo atingir seus objetivos de perda de peso e manutenção desta perda, no caso de Alessandra, seria fundamental que ela modificasse o seu estilo de vida, adquirindo novos hábitos.

Samanta (grau II) minimiza seu tamanho corporal e tem uma insatisfação média. Esta distorção perceptiva pode colaborar para diminuir seu sofrimento pelo seu peso e todas as consequências relacionadas a ele. $\mathrm{Na}$ entrevista afirma não gostar do corpo e sentir-se desconfortável. De acordo com o Questionário dos três fatores alimentares apresenta uma facilidade na perda e manutenção do peso, o que não coincide com a entrevista, pois Samanta afirma lutar muito para atingir o emagrecimento e não consegue. Collins e Sprinthall (2003) afirmam que é comum para os jovens terem sentimentos negativos acerca do seu corpo. A sociedade valoriza muito a aparência física e as pessoas que se sentem fora do padrão socialmente aceito sentem-se tristes ou desconfortáveis, como pode ser observado no relato de Samanta.

Todas as participantes possuem insatisfação corporal, sendo que umas em maior e outras em menor grau. Em relação às expectativas, de mudanças na vida após emagrecimento, todas as participantes independentemente do grau de obesidade, acreditam que seriam mais felizes se fossem mais magras, não sendo possível diferenciar se as participantes com obesidade II são mais insatisfeitas e possuem mais expectativas que as outras, pois os resultados foram mistos e considerou-se a história pessoal de vida de cada uma delas.

\section{Conclusão}

$\mathrm{O}$ estudo possibilitou identificar alguns fatores que podem dificultar a perda de peso, como a falta de tempo, a ansiedade, a baixa autoestima, o fato de ter em casa alimentos altamente calóricos, a interferência da família na adesão ao tratamento, a facilidade para se ganhar peso, a falta de autocontrole e a falta de motivação para mudar o estilo de vida e os hábitos alimentares. Observa-se que, mesmo conscientes dos perigos que a obesidade traz, as participantes sentem dificuldade de por em prática o que sabem.

Existe a crença de que se emagrecessem aumentariam a autoestima, sendo que seria mais fácil para elas atingirem o emagrecimento se gostassem de si mesmas. Assim, é possível pensar que seria mais eficaz a perda de peso se primeiro houvesse uma melhora na autoestima.

A tentativa de emagrecimento acarreta várias perdas, pois o indivíduo deixa de estar presente em contextos sociais para evitar ingerir alimentos, o que pode levá-los ao isolamento social. Deixa também de comer alimentos saborosos que tem um maior teor calórico e passam a alimentar-se de forma mais saudável, porém que não lhes traz prazer. Como o indivíduo evita ingerir alimentos, muitas vezes há um aumento da ansiedade e frustrações, pois ele passa a não mais "descarregar" no alimento as suas tensões. Além disso, para que o emagrecimento ocorra é necessário um longo período de tempo, o que muitas vezes causa um desânimo ao indivíduo por não ver um resultado imediato.

Sendo assim, para Gorayeb e Luiz (2002), tornase fundamental que o indivíduo tenha um preparo emocional para um tratamento demorado. É importante que este construa estratégias de enfrentamento para lidar com as perdas e controlar os sentimentos e impulsos, além de reconstruir seus valores. Passar a realizar atividades físicas regularmente, fazer uma reeducação alimentar, abandonar alguns hábitos e adquirir outros, como restringir o consumo de gorduras, comer apenas quando se estiver com fome e não ficar sem comer por longos períodos fazem parte de uma mudança de estilo de vida que aumenta a possibilidade do indivíduo atingir seus objetivos de perda de peso e manutenção desta perda. A transmissão de informações só alcança a dimensão intelectual, sendo insuficiente, pois a alimentação envolve muito mais do que isso (Ferreira; Cunha \& Oliveira, 2008).

Além de desenvolver hábitos alimentares saudáveis, deve-se também fazer mudanças modestas de peso ao invés de mudanças radicais, pois ser muito rígido pode contribuir para que se desista da dieta, pelo fato de ter que suportar muitas restrições. Ampliar e resgatar pessoas de sua rede social poderia ajudar neste processo. $\mathrm{O}$ apoio social e familiar pode motivá-lo a persistir e ter paciência para atingir suas metas. Além disso, é necessário receber suporte de profissionais da área.

Verificou-se que as entrevistadas alimentam várias expectativas em relação ao emagrecimento, como se este fosse aumentar o amor do companheiro, ou fazêlas subir de cargo na empresa onde trabalham. Seria interessante verificar o quanto essas expectativas são reais ou ilusórias, pois muitos indivíduos acreditam que com o emagrecimento não teriam mais problemas, 
devido ao fato de todos os seus problemas estarem relacionado à obesidade.

É preciso que se desenvolvam formas de intervenção que vão ao encontro das necessidades e demandas dessas pessoas, que estejam mais perto da realidade em que elas vivem e das dificuldades que elas enfrentam no dia a dia. Conclui-se que esta pesquisa pode favorecer para que haja um maior conhecimento por parte dos profissionais da área de saúde e da comunidade em geral sobre as dificuldades que as mulheres obesas podem vir a enfrentar nesse processo de busca do emagrecimento e esclarecer para a população que a obesidade não é uma questão de falta de força de vontade, mas que envolve aspectos biopsicossociais que devem ser trabalhados de forma adequada.

\section{Referências}

Abeso. (2011, Abril 19). O Ministério da Saúde confirma: o número de obesos no país cresce a cada ano. Acessado de

http://www.abeso.org.br/lenoticia/706/o-ministerio-da-saudeconfirma:-o-numero-de-obesos-no-pais-cresce-a-cada-ano.shtm

Almeida, R. J. (2013). Obesidade nos corpos das mulheres e os olhares sobre os discursos medicalizantes. Brasília: Universidade de Brasília - UNB

Bardin, L. (2009). Análise de conteúdo. Tradução Luís Antero Reto e Augusto Pinheiro. Lisboa: Portugal.

Cohen, R.,Cunha, M. R. (2004). A obesidade (p.135-140). São Paulo: Publifolha.

Collins, W. A., Sprinthall, N. A. (2003). Psicologia do adolescente: Uma abordagem desenvolvimentista. Tradução Cristina Maria Coimbra Vieira. Lisboa: Fundação Calouste Gulbenkian.

Donato, A., et al. (2007). Obesidade. In: SALVADOR, R. B. (Org.). Anorexia, Bulimia e Obesidade, (2. Ed., p. 329-366). Barueri, SP.

Erikson, E. H. (1987). Identidade Juventude e Crise. Rio de janeiro: Guanabara.

Erikson, E. H. (1998). O Ciclo de Vida Completo. Tradução Maria Adriana Veríssimo Veronese. Porto Alegre: Artes Médicas.

Ferreira, R. A., Cunha, C. F., Oliveira, T. R. P. R. (2008). Educação nutricional como estratégia de intervenção para $\mathrm{O}$ tratamento da obesidade na adolescência. Rev. Méd. Minas Gerais, 18 (3), 67-75.

Fett, C. A., Feet, W. C. R., Marchini, J. S., Ribeiro, R. P. P. (2010). Estilo de vida e fatores de risco associados ao aumento da gordura corporal de mulheres. Ciência \& Saúde Coletiva, 15 (1).

Flores, L. S., Gaya, A. R., Petersen, R. D. S., Gaya, A. (2013). Tendência do baixo peso, sobrepeso e obesidade de crianças e adolescentes brasileiros. J. Pediatr. (Rio J.), 89 (5) Porto Alegre.

Gonçalves, C. A. O. (2004). "Peso" de ser muito gordo: um estudo antropológico sobre obesidade e gênero. Revista de humanidades, 5 (11), 599-642.

Gorayeb, R., Luiz, A. M. A. G. (2002). Obesidade infantil e depressão, São Paulo.

Gunther, H. (2006). Pesquisa qualitativa versos pesquisa quantitativa: Essa é a questão?. Série: Textos de Psicologia Ambiental, 7, p. 01-08, Brasília.

Junior, F. B. A. (2007). A questão da beleza ao longo do tempo. In: SALVADOR, R. B. (Org.). Anorexia, Bulimia e Obesidade. (2. Ed., p. 01-12). Barueri, SP.

Kac, G., Meléndez, G. V. (2003). A transição nutricional e a epidemiologia da obesidade na América Latina. Cad. Saúde Pública, 19 (1).

Kakeshita, I. S., Almeida, S. S. (2006) Relação entre índice de massa corporal e a percepção da auto-imagem em universitários.
Rev. Saúde Pública, 40 (3).

Meier, M., Ferreira, M. M. (2004). Psicologia do emagrecimento. Rio de Janeiro: Revinter.

Nakamura, E. (2007). Representações sobre o corpo e hábitos alimentares: o olhar antropológico sobre aspectos relacionados aos transtornos alimentares. In: Salvador, R. B. (Org.). Anorexia, Bulimia e Obesidade. (2. Ed., p. 13-29 ). Barueri, SP.

Novaes, J. V. (2005). Ser mulher, ser feia, ser excluída Acessado de http://www.psicologia.pt/artigos/ver_artigo.php?codi $\mathrm{go}=\mathrm{A} 0240 \&$ area $=\mathrm{d} 11 \&$ subarea $=\mathrm{d} 11 \mathrm{~B}$

Nunes, M. A., Apolinário, J. C., Abuchaim, A. L., Coutinho, W. (2006). Transtornos alimentares e obesidade. In Freitas, S. R. Instrumentos para a avaliação dos transtornos alimentares (p. 241248). Porto Alegre: Artmed.

Oliveira, M. L. (2013). Estimativa dos custos da obesidade para o Sistema Único de Saúde do Brasil. Brasília: Universidade de Brasília - UNB.

Pinheiro, G. E. C. C., Maciel, R. H. (2007). A magreza feminina na capa da revista Veja. Revista Digital: Comunicação \& Estratégia, 3 (7).

Pratta, E. M. M., Santos, M. A. (2007). Família e adolescência: A influência do contexto familiar no desenvolvimento psicológico de seus membros. Psicologia em estudo, 12 (2), 247-256.

Rabello, E. T., Passos, J. S. (2010) Erikson e a Teoria Psicossocial do Desenvolvimento. Acessado de http://www. josesilveira.com/artigos/erikson.pdf

Ribeiro, V. L. P. Obesidade e função sexual. (2008). Acessado de http://www.psicologia.pt/artigos/ver artigo.php?codigo=A0407 \&area $=\mathrm{d} 11 \&$ subarea $=$

Scagliusi, F. B., Palacow, V. O. (2006). Aspectos nutricionais da obesidade. In: Junior, A. H. L. (org.) Obesidade: Uma abordagem multidisciplinar (p. 65-95). Rio de Janeiro: Guanabara Koogan.

Silva, G. R. F. Macêdo, K. N. F., Rebouças, C. B. A.; Souza, A. M. A. (2006) Entrevista como técnica de pesquisa qualitativa. Portal de revistas de enfermagem, 5 (2). Rio de Janeiro.

Stein, L. M., Ramos, M. (2000). Desenvolvimento do comportamento alimentar infantil. Jornal de Pediatria. 3 (229).

Vargas, I. C. S., Sichieri, R., Pereira, G. S., Veiga, G. V. (2011). Avaliação de programas de prevenção da obesidade em adolescentes de escolas públicas. Rev Saude Publica, 45 (1), 59-68.

Velloso, L. et al. (2011). Neuroimagem revela alterações no cérebro de pacientes obesos. Jornal da UniCamp. XXV (499).

Venturini, L. P. (2000) Obesidade e família - Uma caracterização de famílias de crianças obesas e a percepção dos familiares e das crianças de sua imagem corporal. São Paulo.

Vigitel. (2011, Maio 1) Acessado de portal.saude.gov.br/ portal/arquivos/pdf/vigitel 180411.pdf

Zanella, M. T.(2006). Obesidade suas causas e efeitos. São Paulo: Alaúde.

Zottis, C., Labronici, L. M. (2003). O corpo obeso e a percepção de si. Curitiba: Universidade Federal do Paraná. 
Sobre os autores:

Ana Paula da Silva Vasques Oliveira - Psicóloga formada pela Universidade Católica de Brasília. Residente em psicologia hospitalar no Hospital de Base do Distrito Federal - HBDF.

E-mail: psi.paula.vasques@hotmail.com

Marília Marques da Silva- Doutora em Psicologia; Docente do Curso de Graduação em Psicologia da Universidade Católica de Brasília.

E-mail: mariliamsilva@gmail.com 